\title{
Life-cycle energy analysis of wind turbines - an assessment of the effect of size on energy yield
}

\author{
R. H. Crawford \\ Faculty of Architecture, Building and Planning, \\ The University of Melbourne, Australia
}

\begin{abstract}
Wind turbines, used to generate non-fossil fuel based electrical power, are typically considered to take only a number of months to produce as much energy as is required in their manufacture and operation. With a life-expectancy of upwards of 20 years, the renewable energy produced by wind turbines over their life can be many times greater than that embodied in their production.

Many previous studies of the life-cycle energy requirements of wind turbines are based on methods of assessment now known to be incomplete. These studies may underestimate the energy embodied in wind turbines by more than $50 \%$, potentially overestimating the energy yield of those systems and possibly affecting the comparison of energy generation options.

With the increasing trend towards larger scale wind turbines comes a respective increase in the energy required for their manufacture. It is important to consider whether or not these increases in wind turbine size, and thus embodied energy, can be adequately justified by equivalent increases in the lifetime energy yield of such systems. This paper presents the results of an assessment of the effect of wind turbine size on their life-cycle energy yield and addresses the issue of incompleteness associated with many past life-cycle energy studies.

Energy yield ratios of 21 and 23 were found for a small and large scale wind turbine, respectively. This represents an $11 \%$ increase in the energy yield ratio of the larger turbine over that of the smaller turbine. The embodied energy component was found to be more significant than in previous studies, emphasised here due to the innovative use of a hybrid embodied energy analysis method. The life-cycle energy requirements were shown to be offset by the energy produced within the first 12 months of operation.

Keywords: life-cycle energy, wind turbines, embodied energy, energy yield.
\end{abstract}




\section{Introduction}

Rapid advances in wind turbine technology and materials are leading to an increase in the size and output of wind turbines, maximising the efficiencies of scale and potential energy output. With this trend towards larger scale turbines comes a respective increase in the energy required for their manufacture, assuming similarly energy intensive materials.

Previous life-cycle energy studies of wind turbines have typically assumed that these systems pay back the energy invested in them within several months. While the energy requirements have been shown to be relatively insignificant in comparison to the energy generated, there is significant variability in the embodied energy values presented. This variation may be due to problems with the embodied energy analysis methods used.

Traditional methods of quantifying embodied energy, namely process analysis and input-output (I-O) analysis, have been shown to have significant limitations, despite the different benefits each method offers. The most important stage of an embodied energy analysis is the quantification of the inputs to the product or system. Traditionally, a boundary has been drawn around the quantification of inputs to the product being assessed, mainly due to difficulties in obtaining necessary data and the understanding of this data. Many inputs are therefore neglected, and thus the system is incomplete.

Due to the inherent problems with process analysis and I-O analysis, hybrid methods of embodied energy analysis have been developed in an attempt to minimise the limitations and errors of these traditional methods. This study uses an I-O-based hybrid analysis method in determining the life-cycle energy requirements and energy yield of two on-shore wind turbines of varying size and output. The aim of this study was to determine whether the trend towards larger scale wind turbines is having a significant impact on their energy yield, through the improved economies of scale and higher rated outputs, despite potential increases in embodied energy.

\section{Background}

A life-cycle energy analysis of a wind turbine involves a study of the energy flows over its entire life. This includes the embodied energy associated with the manufacturing process and subsequent replacement and repair of components; the energy required for operation, maintenance and disposal; and the energy generated by the turbine over its entire life. Traditionally, the energy output has been the focus of studies dealing with the life-cycle energy of wind turbines. This may be partly due to conceptual failure in quantifying the life-cycle energy requirements of these systems through underestimating the possible importance of embodied energy. Embodied energy is particularly important due to the complexity of the supply chain. This complexity means that the supply chain has to be modelled for each product and process upstream to the raw materials.

There have been numerous studies that have considered the energy requirements and energy output associated with wind turbines in order to 
determine the overall environmental benefit from these systems. The findings from these studies tend to vary considerably depending on a number of key factors, including: the method of embodied energy assessment chosen; the system boundary; and the life-cycle stages considered.

\subsection{Embodied energy}

An important component of the energy requirements of a wind turbine is the energy embodied in their manufacture, construction, installation, maintenance, and parts replacement. This embodied energy can account for a significant proportion of the life-cycle energy requirements for particular products [1].

There is a considerable amount of variability in the figures provided in the past for the embodied energy of wind turbines, typically considered to be the most significant area where variation between life-cycle energy studies occurs [2]. Past studies have shown embodied energy values ranging from 3,948 GJ for a $500 \mathrm{~kW}$ system [3] to 15,495 GJ for a 3.0 MW system [4]. Many of these previous studies have indicated that the energy embodied in a wind turbine may equate to less than $5 \%$ of the energy generated during their service life.

Whilst turbine size, materials used, energy intensities and location will have an impact, the major reason for the variability in embodied energy figures is due to the method of assessment chosen. When calculating the embodied energy of wind turbines, previous studies have traditionally used process-based methods of assessment. These methods consider the energy requirements for only a limited number of inputs, usually the main materials, and fail to account for other inputs, accounting for up to $80 \%$ of the total embodied energy [5]. With this incomplete system boundary, the errors typically associated with assessing these energy requirements may be exacerbated even further. This may then lead to incorrect findings, in particular, greater energy yields, shorter energy payback periods and greater environmental benefits than are actually possible.

Hybrid methods have been developed in an attempt to minimise the limitations and errors of traditional embodied energy assessment methods. National average statistics that model the financial flows between sectors of the economy, referred to as I-O data, can be used to fill the gaps that are caused by system boundary incompleteness [6]. These hybrid methods combine process data and I-O data in a variety of formats $[6,7]$. Lenzen and Munksgaard [2] and Crawford et al [8] have demonstrated that the use of an I-O-based hybrid technique is the preferred method for the assessment of the energy content of renewable energy systems, such as wind turbines, in order to achieve system completeness, thus minimising the limitations of previous studies.

\subsection{Energy yield}

Many previous studies considering the net energy production associated with wind turbines have based these assessments on the time required for the lifecycle energy requirements to be paid back by the energy produced (known as the energy payback period). Richards and Watt [9] have highlighted the deficiencies in this type of approach to assessing the benefits of energy generation 
technologies. Richards and Watt [9] and Pick and Wagner [3] suggest that the energy yield ratio (EYR) provides a more informative indication of the potential energy savings possible. The EYR shows how many times the energy invested in the wind turbine is returned or paid back by the system in its entire life [3].

Varying results have been presented for the EYR of wind turbines. This variation can be attributed to a number of key variables, including: the materials used and their embodied energy; assessment method used; geographic location; service life; capacity factor; and power rating [10]. The EYRs that have been presented in the past vary from 10 [11] to 70 [3]. The variation in yield ratio between different sized turbines has been shown to vary by as little as $10 \%$ $[3,11]$ and thus the scale of a turbine may have little impact on its energy yield.

This paper presents the results of an assessment of the effect of wind turbine size on life-cycle energy yield and addresses the issue of incompleteness associated with many past life-cycle energy studies of wind turbines.

\section{Methodology}

This section describes the wind turbines chosen for the study and outlines the methods used to calculate the life-cycle energy requirements and energy yield of these wind turbines.

\subsection{System details}

The main components of the wind turbines include: rotor (hub and blades), nacelle (generator, gearbox, brakes, electronic controller, transformer, and control system), tower and base. Two wind turbines, of varying height and rated output have been chosen for this study. These turbines are horizontal axis, 3 blade systems with an anticipated service life of 20 years. The main features of these turbines are shown in Table 1.

Table 1: Wind turbine characteristics.

\begin{tabular}{lcc}
\hline & Wind Turbine 1 & Wind Turbine 2 \\
& $850 \mathrm{~kW}$ & $3.0 \mathrm{MW}$ \\
\hline Total rated power output $(\mathrm{kW})$ & 850 & 3000 \\
Capacity factor & $34 \%$ & $33 \%$ \\
Cut-in wind speed & $4 \mathrm{~m} / \mathrm{s}$ & $4 \mathrm{~m} / \mathrm{s}$ \\
Cut-out wind speed & $25 \mathrm{~m} / \mathrm{s}$ & $25 \mathrm{~m} / \mathrm{s}$ \\
Hub height & $60 \mathrm{~m}$ & $80 \mathrm{~m}$ \\
Blade length / rotor diameter $(\mathrm{m})$ & $25 / 52$ & $44 / 90$ \\
\hline
\end{tabular}

A number of important assumptions were also used in the analysis:

- $\quad$ wind velocity distribution is based on Weibull's distribution;

- $\quad$ component replacement scenario based on Vestas Wind Systems [4] equivalent to the replacement of half of the gearbox over the service life; 
- materials required for maintenance have been included, i.e. change of oils and lubricants every 5 years; and

- $\quad$ energy requirements and savings associated with decommissioning or use of recycled materials have not been included.

\subsection{Life-cycle energy}

For the purpose of this study and the comparison between systems, the period of the life-cycle energy analysis chosen was 20 years. This period corresponds with the stated design life of the turbines studied. The main structural components of a turbine (such as the tower and base) are capable of lasting many years beyond this, however, more regular replacement of the moving parts, such as the generator, gearbox and blades is generally required [4]. The energy produced over the life-cycle of each wind turbine is equal to the gross energy output of the turbine, minus the initial embodied energy, the energy associated with the necessary replacement during the 20-year period and the energy required for operation, maintenance and repair.

\subsubsection{Embodied energy}

The embodied energy of a wind turbine includes the energy required in the manufacturing, construction, installation and ongoing maintenance stages. When considering these wind turbines as part of a wind farm, with a multiple number of turbines, this embodied energy may also include the energy required for other materials and components, including wiring, grid connection, transformers and access roads. For this study, these components have not been included as they are considered to be insignificant or equivalent for each scenario and thus have no impact on the comparison of net energy production and yield [4].

The quantities of materials used in the manufacture of each of the turbines were determined. The embodied energy values were derived using an I-O-based hybrid analysis method, as described by Treloar [6], using I-O data for Australia for the financial year 1996-97 and available process data. Hybrid material embodied energy intensities were multiplied by the quantities of basic materials. These individual material embodied energy figures were then summed to obtain an initial estimation of the embodied energy value for the turbines.

An energy-based I-O model, based on more than 100 sectors of the Australian economy was then used to complete the system boundary. The I-O model was disaggregated to allow the quantified material inputs to be subtracted, leaving a remainder that was applied to the study in a holistic manner to fill all the remaining gaps, as demonstrated by Treloar et al [12]. The initial embodied energy value was then added to this figure to give the total embodied energy using I-O-based hybrid analysis.

\subsubsection{Energy output}

The quantity of energy generated by a wind turbine is dependent on a number of factors, including: geographic location; type of system; tower height; rated energy output; and system efficiency. 
The climate of the chosen location for the wind turbines has a significant impact on their energy output. An on-shore site was selected for the location of the wind turbines in this study, on the south-west coast of Victoria, Australia (latitude $37.3^{\circ} \mathrm{S}$ ). The average annual wind speed for this site was $7.75 \mathrm{~m} / \mathrm{s}$. The annual gross energy output of the wind turbines was calculated using the hourly wind data of the chosen location and characteristic power curve of the two wind turbines. Capacity factors of $34 \%$ and $33 \%$ for the $850 \mathrm{~kW}$ and $3.0 \mathrm{MW}$ systems respectively, were also used.

The gross energy output was then converted to net annual output by subtracting the energy required for internal controls and day-to-day maintenance and system losses, assumed to be approximately $10 \%$. As these initial output figures were in delivered energy terms, they were then converted to primary energy terms, using a factor of 3.4 to represent the substituted primary energy supplied by the brown coal fired electricity network in Victoria, Australia.

\subsection{Energy yield}

The initial and recurring embodied energy and total net output were combined to determine the energy yield. The energy yield ratio was calculated using the following equation:

$$
E Y R=\frac{E_{\text {out }} \times L}{E E_{\text {in }+ \text { rec }}}
$$

where:

$E_{\text {out }} \quad=$ annual net energy output;

$L \quad=$ wind turbine service life; and

$E E_{\text {in }+ \text { rec }} \quad=$ initial and recurring embodied energy requirements.

The respective energy yield ratios of the two wind turbines were then able to be compared and evaluated to determine the impact of a wind turbine's rated output on its energy yield.

\section{Results and discussion}

This section describes the results of the evaluation of the effect of wind turbine size on their potential energy yield. The embodied energy, annual energy output and life-cycle energy production of the two wind turbines, as well as their anticipated energy yield are presented.

\subsection{Embodied energy}

The embodied energy of the two wind turbines, calculated using the I-O-based hybrid analysis method is shown in Table 2 . The embodied energy represented by I-O data is shown to account for at least $74 \%$ of the total for both wind turbines. This represents the gap, or incompleteness associated with a traditional process analysis, on which many previous studies are based. 
Table 2: $\quad$ Embodied energy of wind turbines.

\begin{tabular}{lcc}
\hline & Wind turbine 1 & Wind turbine 2 \\
& $850 \mathrm{~kW}$ & $3.0 \mathrm{MW}$ \\
\hline Initial embodied energy (GJ) & 27,158 & 84,237 \\
Recurring embodied energy (GJ) & 2,230 & 7,939 \\
Embodied energy /MW rated output (GJ) & 34,574 & 30,725 \\
\hline
\end{tabular}

These embodied energy figures are at least six times more than the figures presented in the past, for equivalent size turbines [4]. Previous studies have indicated that the embodied energy of a wind turbine may equate to less than $5 \%$ of the energy generated during their service life. This study shows that whilst the embodied energy figures have increased significantly over those presented in the past, this is still the case.

Figure 1 shows a component level breakdown of the embodied energy of the $850 \mathrm{~kW}$ turbine. The 'other items' represents those inputs that are typically excluded in previous best-practice process-based studies, in this case representing over half of the total embodied energy. The tower makes up the next largest proportion of the embodied energy of this turbine $(25 \%)$.
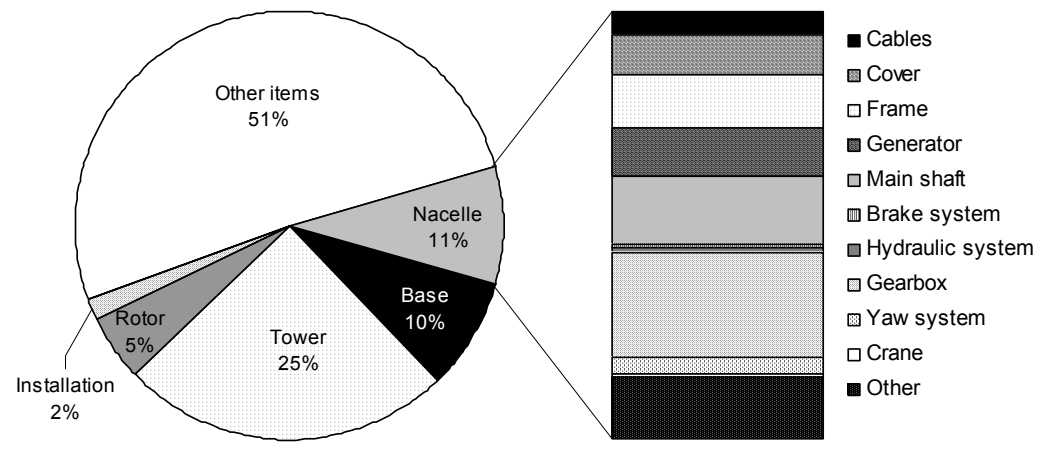

Figure 1: $\quad$ Embodied energy of $850 \mathrm{~kW}$ wind turbine, by component.

The breakdown of the embodied energy of the 3.0 MW turbine (Figure 2) shows that the 'other items' represent a slightly larger proportion of the total embodied energy (59\%). As for the smaller turbine, the tower makes up the second largest proportion of the embodied energy of this turbine, at $18 \%$. Installation represents only $2 \%$, whilst the gearbox represents almost one third of the embodied energy associated with the nacelle. 

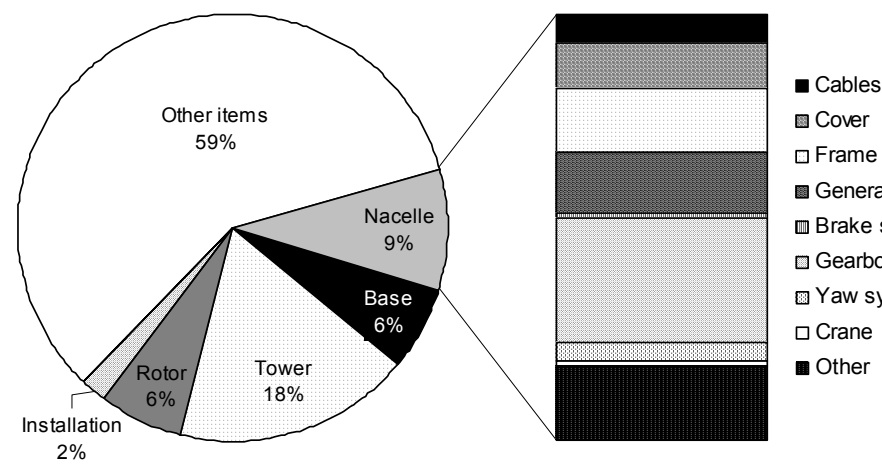

$\square$ Cover

$\square$ Frame

Generator

๑ Brake system

$\square$ Gearbox

$\square$ Yaw system

$\square$ Crane

- Other

Figure 2: $\quad$ Embodied energy of 3.0 MW wind turbine, by component.

\subsection{Annual energy output}

The annual gross and net energy output, in primary energy terms, of each wind turbine is shown in Table 3. The net energy output was determined by subtracting the energy required for internal controls and day-to-day maintenance from the gross output.

Table 3: $\quad$ Annual energy output of wind turbines, in primary energy terms.

\begin{tabular}{lrc}
\hline & $\begin{array}{c}\text { Wind turbine } 1 \\
850 \mathrm{~kW}\end{array}$ & $\begin{array}{c}\text { Wind turbine 2 } \\
3.0 \mathrm{MW}\end{array}$ \\
\hline Gross annual output $(\mathrm{MWh})$ & 9,486 & 32,915 \\
Net annual output $(\mathrm{MWh})$ & 8,571 & 29,743 \\
Specific yield $\left(\mathrm{kWh} / \mathrm{m}^{2}\right)$ & 4,036 & 4,675 \\
\hline
\end{tabular}

\subsection{Life-cycle energy analysis and energy yield ratio}

Considering a total service life of 20 years for the two systems studied, the total net life-cycle energy produced (net life-cycle output minus the embodied energy and energy required for maintenance and operation) and the energy yield, were determined. The net life-cycle energy produced over a 20 -year period was $588 \mathrm{TJ}$ and $2049 \mathrm{TJ}$ for the $850 \mathrm{~kW}$ and $3.0 \mathrm{MW}$ wind turbines, respectively. Based on an emissions factor of $60 \mathrm{~kg} / \mathrm{GJ}$, this equates to a saving of $35,265 \mathrm{t}$ and $122,960 \mathrm{t}$ of greenhouse gases for the $850 \mathrm{~kW}$ and 3.0 MW turbines over their service life, respectively.

The EYR ranges from 21 for the $850 \mathrm{~kW}$ turbine to 23 for the $3.0 \mathrm{MW}$ turbine (Figure 3). This shows that both turbines produce a significantly larger amount of energy than is required for their manufacture, operation and maintenance during their effective life. These EYRs are expected to increase to 32 and 35 for a service life of 30 years, as seen in Figure 3, demonstrating the potential benefits of maximising wind turbine service life. 


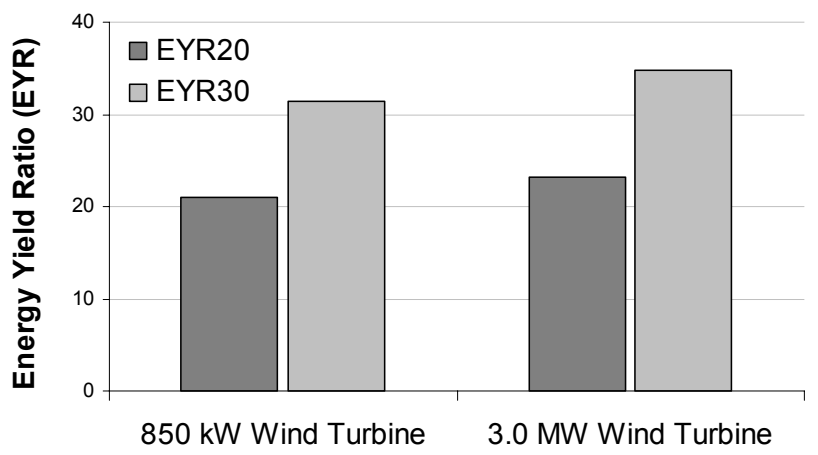

Figure 3: $\quad$ Energy yield ratio of $850 \mathrm{~kW}$ and 3.0 MW wind turbines.

Whilst the larger 3.0 MW system has been shown to provide a higher EYR, the $11 \%$ increase is not considered to be significant. The size of a wind turbine therefore may have little influence on its potential energy yield.

The energy yield of these turbines may vary with the recovery of energy from the reuse or recycling of components and materials. However, it is not considered that this would significantly influence the energy yield, considering the small proportion of the life-cycle energy that the embodied energy represents.

Whilst energy is a useful indicator of the environmental impacts of wind turbines, other factors should also be considered. These are typically the focus of a much broader life-cycle assessment study.

\section{Conclusions}

The aim of this study was to determine the impact of wind turbine size on energy yield. It was thought that the increase in embodied energy for larger scale turbines may have adversely affected their potential energy yield, despite increased energy output. This study has shown, by analysing the energy requirements and production of two varying sized wind turbines, that there is no significant difference in the energy yield between small and large scale turbines, particularly considering the errors associated with this type of assessment. However, other benefits exist for the use of larger scale wind turbines, such as the ability to reduce the required footprint area per unit of rated output.

The use of a systemically complete hybrid embodied energy analysis method has shown that previous embodied energy assessments of wind turbines may be up to $78 \%$ incomplete. Despite these significant improvements in embodied energy assessment, the relative insignificance of the embodied energy component of wind turbines over their service life has been highlighted. 


\section{Acknowledgements}

Part of this work was supported by an Australian Research Council Linkage grant, LP0667653 with industry partner Williams Boag Architects, Melbourne.

\section{References}

[1] Crawford, R.H., Validation of the Use of Input-Output Data for Embodied Energy Analysis of the Australian Construction Industry, Journal of Construction Research, 6(1), pp. 71-90, 2005.

[2] Lenzen, M. \& Munksgaard, J., Energy and $\mathrm{CO}_{2}$ Life-Cycle Analyses of Wind Turbines - Review and Applications, Renewable Energy, 26, pp. 339-362, 2002.

[3] Pick, E. \& Wagner, H.J., Cumulative Energy Demand (CED) and Energy Yield Ratio for Wind Energy Converters, Proceedings: World Renewable Energy Congress VII, Cologne, 5p, 2002.

[4] Vestas Wind Systems, Life-Cycle Assessment of Offshore and Onshore Sited Wind Power Plants Based on Vestas V90-3.0 MW Turbines, Report, Denmark, July, 60p, 2006.

[5] Crawford, R.H., Validation of a Hybrid Life-Cycle Inventory Analysis Method, Journal of Environmental Management, in press.

[6] Treloar, G.J., Extracting Embodied Energy Paths from Input-Output Tables: Towards an Input-Output-Based Hybrid Energy Analysis Method, Economic Systems Research, 9(4), pp. 375-391, 1997.

[7] Bullard, C.W., Penner, P.S. \& Pilati, D.A., Net Energy Analysis: Handbook for Combining Process and Input-Output Analysis, Resources and Energy, 1, pp. 267-313, 1978.

[8] Crawford, R.H., Treloar, G.J., Fuller, R.J. \& Bazilian, M., Life-Cycle Energy Analysis of Building Integrated Photovoltaic Systems (BiPVs) with Heat Recovery Unit, Renewable and Sustainable Energy Reviews, 10(6), pp. 559-575, 2006.

[9] Richards, B.S. \& Watt, M.E., Use of the Energy Yield Ratio as a Means of Dispelling one Myth of Photovoltaics, Proceedings: Australian and New Zealand Solar Energy Society (ANZSES) Solar 2004 Conference, Perth, November, 9p, 2004.

[10] European Commission, ExternE: Externalities of Energy Vol. 6: Wind and Hydro, Report No. EUR 16525, Office for Official Publications of the European Commission, Luxembourg, 252p, 1995.

[11] Gurzenich, D., Mathur, J., Bansal, N.K. \& Wagner, H.J., Cumulative Energy Demand for Selected Renewable Energy Technologies, International Journal of Life Cycle Assessment, 4(3), pp. 143-149, 1999.

[12] Treloar, G.J., Love, P.E.D. \& Holt, G.D., Using National Input-Output Data for Embodied Energy Analysis of Individual Residential Buildings, Construction Management and Economics, 19, pp. 49-61, 2001. 